\title{
E-SMART SYSTEM FOR IN-SITU DETECTION OF ENVIRONMENTAL CONTAMINANTS
}

RECEIVEO APR 201998

\section{QUARTERLY TECHNICAL PROGRESS REPORT}

OSTI

General Atomics

PO Box 85608

San Diego, California 92186-9784

Work Performed Under

DOE Cooperative Agreement DE-FC0795ID13352

U.S. Department of Energy Idaho Operations Office Idaho Falls, Idaho

Effective Date of Contract: Contract Expiration Date: Reporting Period:
March 20, 1995

September 1, 1998

Q4CY97 (October-December 1997)

GENERAL ATOMICS PROJECT $3719 / 4450$ March 30, 1998

DISTRISUTION OF THS DOCLMENT IS UNMATED 


\section{DISCLAIMER}

Portions of this document may be illegible in electronic image products. Images are produced from the best available original document. 


\section{Contents}

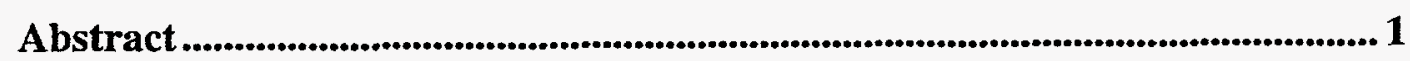

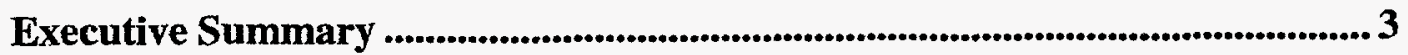

1. Work Conducted October-December, 1997 .............................................. 4

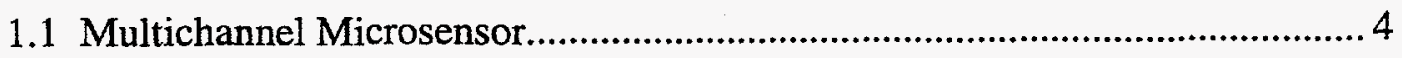

1.2 Sawtek Integrated Modular Array Sensor (IMAS) .................................... 7

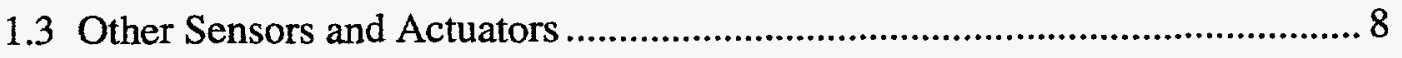

1.4 E-SMART Network Management ..................................................... 9

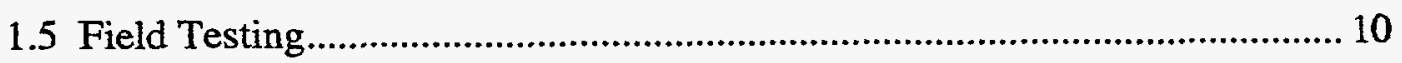

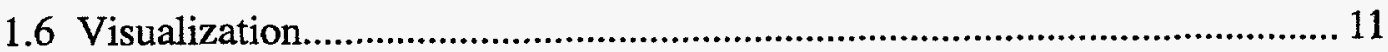

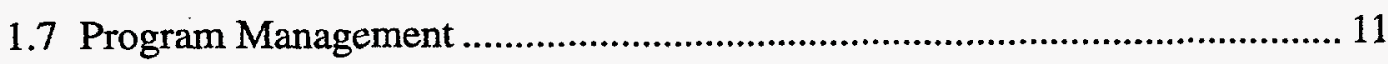

1.8 Dual Use and Commercialization ...................................................... 11

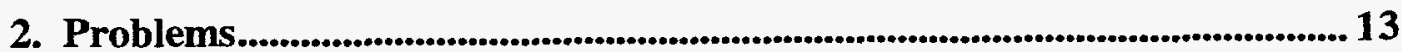

3. Plans for the Next Quarter ............................................................................. 13

4. Milestones and Deliverables .................................................................... 13

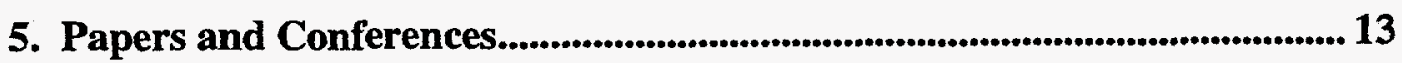

6. Financial Status Report .................................................................................. 13

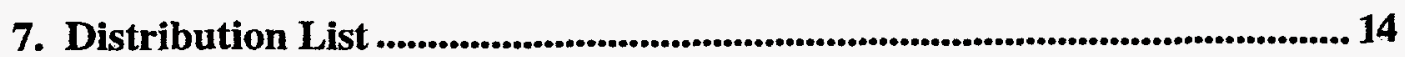




\begin{abstract}
General Atomics (GA) leads a team of industrial, academic, and government organizations in the development of the Environmental Systems Management, Analysis and Reporting neTwork (E-SMART) for the Defense Advanced Research Project Agency (DARPA), by way of this Technology Reinvestment Project (TRP). E-SMART defines a standard by which networks of smart sensing, sampling, and control devices can interoperate. E-SMART® is intended to be an open standard, available to any equipment manufacturer. The user will be provided a standard platform on which a site-specific monitoring plan can be implemented using sensors and actuators from various manufacturers and upgraded as new monitoring devices become commercially available.

GA's TRP team members include Isco, Inc., Photonic Sensor Systems, Inc. (PSS), Georgia Tech Research Institute (GTRI), Secor, Inc. (SECOR), Biode, Inc (Biode), Rapid Clip Neural Systems, Inc. (RCNS), Applied Research Associates, Inc. (ARA) and the U.S. Air Force Armstrong Laboratory Environics Directorate at Tyndall AFB(AL). Government interests are also represented by program managers from DARPA, DOE EM-53, and DOE-Idaho.
\end{abstract}

This DARPA TRP project will further develop and advance the E-SMART standardized network protocol to include new sensors, sampling systems, and graphical user interfaces. Specifically, the E-SMART team will develop the following three system elements:

A new class of smart, highly sensitive, chemically-specific, in-situ, multichannel microsensors utilizing integrated optical interferometry technology,

A set of additional E-SMART-compatible sensors and samplers adapted from commercial off-the-shelf technologies as well as a developmental sensing technologies contributed by Biode, Inc. and Sawtek, Inc.(see below), and

A Data Management and Analysis System (DMAS), including network management components and a user-friendly graphical user interface (GUI) for data evaluation and visualization.

General Atomics has signed Articles of Collaboration with another DARPA TRP awardee, Sawtek, to develop an E-SMART-compatible version of the Sawtek Intelligent Modular Array System (IMAS) for monitoring volatile organic chemicals (VOC's) in the environment. This collaboration will simplify the network development required to field the IMAS sensor, and will encourage the adoption of the E-SMART standard by increasing the number of commercially available E-SMART sensors. The Sawtek team now also includes Perkin-Elmer.

Figure 1 summarizes the vision and goals of the E-SMART TRP project. 
GA-C22131

E-SMART TRP

Q4 CY97

E-SMART TRP

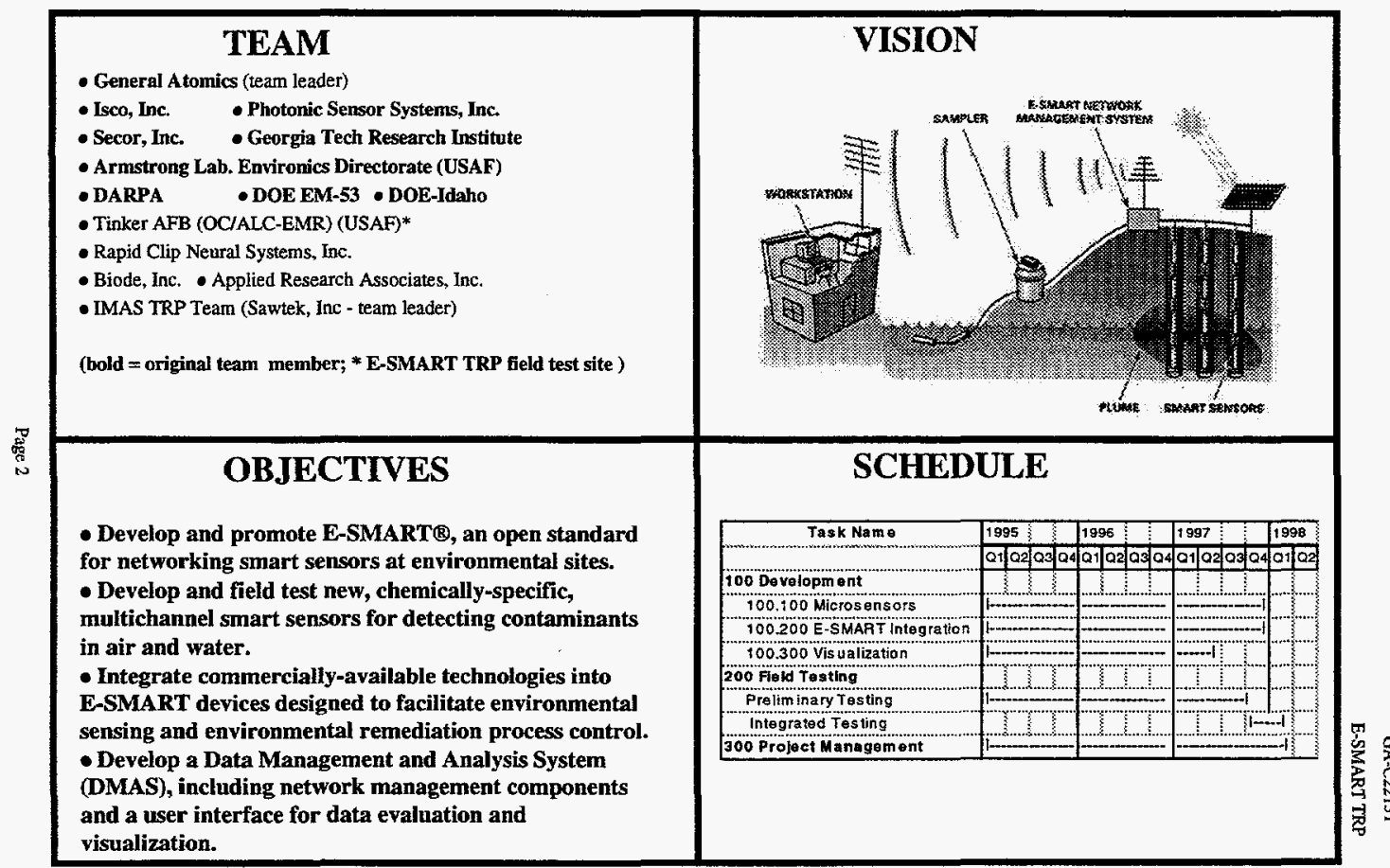

Fig. 1. Quad Chart Summarizing the E-SMART Project 


\section{Executive Summary}

\section{Program Management}

- A team meeting was held at Isco in Lincoln, Nebraska on November 18, 1997

- Additional meetings were held in Atlanta between PSS, GTRI and Isco personnel

- Planning for a field demonstration in March 1998 continued

- The General Atomics program manager met with Dr. Ira Skurnick of DARPA in December 1998 to discuss program progress

\section{Multichannel Microsensor}

- Testing at GTRI and Isco revealed problems with the preliminary E-SMART microsensor heads due to "polymer aging" effects

- Good progress was made on the microsensor electronics and firmware

\section{Sawtek Integrated Modular Array Sensor (IMAS)}

- A serial gateway concept was developed to support IMAS integration with E-SMART

\section{Other Sensors and Actuators}

- BIODE has assembled and is laboratory testing the final benchtop prototype of its mercury sensor.

- A second revision of the new Smart Device Processor (SDP II) board was designed

\section{E-SMART Network Management}

- A new version of the E-SMART network management software was developed and installed at Isco in November

\section{E-SMART Field Testing}

- The E-SMART network continues to operate at Tinker AFB. No data analysis is currently being performed pending additional support from other sources.

Maintenance of the network continues at a low tempo. It is expected that the continued operation of the sensors will contribute to an understanding of aging effects and operational issues for in situ sensors.

\section{Dual Use and Commercialization}

- Armstrong Laboratory, Tinker AFB, and General Atomics presented a poster presentation on E-SMART at the $3^{\text {rd }}$ Annual SERDP Symposium in December, 1997. 
- Draft bylaws were developed for the E-SMART Standards Organization (See Appendix A). This organization is intended to promote the use of E-SMART sensors and other E-SMART products.

\section{Work Conducted October-December, 1997}

\subsection{Multichannel Microsensor (PSS/GTRI)}

WBS 100.110 - Develop Requirements and Design Configuration

This task was completed last quarter (July-September of 1997).

\section{WBS 100.120 - Develop Coatings \& Identify Interferants}

This task was previously completed.

WBS 100.130 - Design and Develop Glass Waveguides

This task was previously completed.

\section{WBS 100.135 - Develop Sensor Protective Techniques}

This task was completed last quarter (July-September of 1997).

\section{WBS 100.140 - Characterize Prototype Sensors}

Testing at GTRI and Isco using several of the final field prototype E-SMART sensors demonstrated good measurement-to-measurement reproducibility when the sensors were operated for periods of up to a week. However, a slow decay in sensitivity became apparent after operation for more than a week. The decay seems to come from an "aging" of the BTEX-selective sensing polymers. These polymers are attached to the surface of the integrated optic detector chip in the sensor by mixing silane molecules into the polymers before putting them on the chip. The silane molecules convalently attach to hydroxyl groups on chip surface, anchoring the polymers to the surface. It is believed that the residual silane molecules not attached to the chip surface slowly cross-link over time, and the cross-linking increasingly inhibits absorption of analytes into the polymer. Several modifications to the attachment procedure have either failed to eliminate the 
aging or have resulted in the polymer being inadequately attached to the chip. The GTRI team is focused on solving this critical-path problem.

Susceptibility to interferants, $\mathrm{pH}$, temperature, pressure and other environmental effects remains to be characterized. General Atomics has been asked to arrange for approximately 5 liters of groundwater from a sampling well at Tinker AFB to be sent to GTRI to support final sensor characterization.

\section{WBS 100.150 — Design Microsensor Electronics \& Packaging}

A signal processing algorithm for translating E-SMART sensor raw outputs into cumulative phase shifts was developed. The algorithm converts 128 pixel intensities to five cumulative phase shifts-one associated with each of the four BTEX-selective sensing polymers and one associated with a buried reference. A methodology for determining the "as-build" sensor parameters used by the algorithm was also developed. Isco code implementing the signal processing algorithm has been exhaustively tested using both a version running on a standalone personal computer and a version running on an E-SMART controller. Both versions generate smooth plots of phase shift versus time for raw data acquired by an E-SMART sensor, and the cumulative phase shifts generated are in good agreement with hand calculations. It appears that only a few minor bugs remain.

Development of pattern recognition software to translate the cumulative phase shifts generated by the signal processing algorithm into BTEX concentrations is the major remaining task for completion of the microsensor electronics. As previously reported, the bulk of this effort has been subcontracted to Rapid Clip Neural Systems (RCNS). Two gradient programmer/reciprocating pump assemblies have been set up at GTRI to generate final BTEX and interferant calibration data for RCNS. Unfortunately, problems with the BTEX-selective sensing polymers has prevented GTRI from beginning the final calibration runs. (See Task Number 100.140.)

\section{WBS 100.170 - Build and Test Preliminary Microsensor Model}

This task was completed last quarter (July-September of 1997).

\section{WBS 100.180 - Build Field Prototype Sensors}

All of the components for the final field prototype E-SMART sensor heads have been fabricated or procured. Five of the ten sensor heads have been fully assembled and 
operated. Final assembly of all ten sensors heads awaits acceptable results from characterization tests using the initial five sensors. (See Task Number 100.140.)

WBS 100.191 — Microsensor Support (Isco)

Attended the TRP status review meeting at GTRI/PSS in Atlanta (October 1997).

\section{WBS 100.192 - E-SMART/LonWorks Interface (Isco)}

Wrote program to test Neuron circuit board.

\section{WBS 100.193 - Embedded Software (Isco)}

\section{October 1997:}

The PC-version of the program PIX2PHI which converts photodiode pixel intensities to interferometric phase shift angles was written. For speed, the internal arithmetic is done in long integers instead of floating point. It is written in C according to PSS's algorithm. The code was successfully tested on both synthetic data and real data collected at GTRI. The final version (PIX2PHIH) of the program was sent to GTRI on 24 October 1997 via e-mail. This $\mathrm{C}$ code was successfully compiled for the Hitachi processor. Its typical execution time per 128-pixels is under 0.3 seconds on the Hitachi processor. The code now needs to be integrated with the rest of the Hitachi software.

November 1997:

Continued testing the pixel-to-phi conversion code in the Hitachi environment. For at least two cases, the code in the Hitachi environment gives the same values (up to 8 significant figures) as the code under the PC environment. Also collected more data using toluene-saturated water and a gradiant programmer. The results from these data as converted by code under both environments give the same results. There was a problem with wrong pixel assignments, but this was rectified. Also pixel saturation appears to be another problem which is currently being addressed.

December 1997:

Continued testing the pixel to phase software. Began serial communication software between the Hitachi and Neuron processors.

\section{WBS 100.194 — Probe with Electronics and Optics (Isco)}

October 1997:

Completed the design of the probe housing and the front CB mounting bracket. Added a desiccant holder/rear CB mount to the design. Changed the design of the endcaps to accommodate a thermistor in one end cap and the connector selected by GA in the other. 
Sent drawings to Prototype. Designed and built a second flowcell to flow BTEX gradients across waveguides. Tested and sent two sets of probe electronics to GTRI. Assembled 14 more sets of Hitachi and Neuron circuit boards.

November 1997:

Continued work on the probe housing and its components including some redesign. Worked with several vendors on welding/soldering the waveguide holder to the tube portion of the probe housing to produce a straight probe housing. Assembled one probe including a probe housing, a partial waveguide/optical bench assembly, endcaps and other components for viewing at the November progress meeting. Began checking out the remaining probe controllers.

December 1997:

Continued work with the vendor on welding the waveguide holder to the tube portion of the probe housing to produce a straight probe housing. Tested the probe housings for leaks. Numerous leaks were found at the weldaments. Identified the locations of the leaks and worked with the vendor closing them. Did further testing for leaks. Made new waveguide holders and tubes to replace those housings that did not properly pass the leak tests. After testing all but one set of controller boards, only two Neuron boards are not operational.

WBS 100.195 - PC-based E-SMART Software (Isco)

No activity this period.

\section{WBS 100.196 — Lab/Local Testing (Isco)}

A single polymer microsensor head was tested at different calibrated concentrations of xylene using an Isco gradient system and a flowcell designed and fabricated for the test. Ran toluene gradients on three probes. Ran tests on one probe with toluene to verify the wavemap and pixel to phase software.

\subsection{Sawtek Integrated Modular Array Sensor (IMAS)}

Sawtek hosted a meeting of the IMAS TRP Coordinating Committee in Orlando, Florida the 21-22 of August. GA attended, as did a representative from Perkin-Elmer, Sandia National Laboratory, and Pacific Northwest Laboratories. The IMAS team discussed the current status of the sensor technology, results of laboratory testing, requirements for E-SMART integration, and field demonstration opportunities. The team expressed strong support for participating in the E-SMART TRP demonstration in 1998. 


\subsection{Other Sensors and Actuators (GA, Biode)}

\section{WBS 100.200 - E-SMART Integration}

Work continued on a new Smart Device Processor design that includes a 32 bit coprocessor and is compatible with the new GA sensor housing design. Based on debugging activities, the SDP II board was redesigned to incorporate necessary fixes and minor enhancements. The new SDP may also be used to support the Sawtek and Biode sensor technologies. 


\section{BIODE, Inc.}

- BIODE has assembled and is laboratory testing the final benchtop prototype of the mercury sensor. These tests employ a solenoid-controlled sample multiplexing system with multiple concentrations of metal. Solution flow-through is employed at $<1 \mathrm{ml}$ per minute.

- BIODE is evaluating modifications of circuit subassemblies prior to the layout of a 1.3" form-factor E-SMART daughter card. The E-SMART daughter card will initially employ an RS-232 serial gateway but will be capable of connecting to the SDP motherboard via queued serial peripheral interface (QSPI).

- BIODE is completing sensor head design for a combined mercury / temperature sensor which will reside in modified down-well cylinders. Current effort is focussing on the inclusion of automatic gain control for oscillator stability, the use of differential amplifiers to reduce electromagnetic interference (EMI) susceptibility and the ability to place the sensor head on a 1.3"diameter printed circuit board.

- Initial electrochemistry tests indicate that $\mathrm{Cr}$ (VI) can be detected using the proposed sensor. Overlap between the responses to $\mathrm{Cr}(\mathrm{VI})$ and $\mathrm{Cr}$ (III) can only exist in that the electrochemistry converts between these species on the electrode during $\mathrm{Cr}(\mathrm{VI})$ detection. This could result in the local conversion of $\mathrm{Cr}$ (VI, aq) into $\mathrm{Cr}$ (III, aq). Cr(III, aq) cannot be converted into $\mathrm{Cr}$ (VI) in this sensor, eliminating concern over the creation of toxic byproducts. More effort is required relative to the effects of $\mathrm{pH}$ and other influences on the $\mathrm{Cr}(\mathrm{VI})$ detection dynamics.

- Progress has been made on the design and manufacture of more sensitive STW sensing elements; however, TRP demonstration will employ the existing quartz SHAPM.

\section{Biode Work Planned for Q1, 1998}

- Continue mercury testing.

- Finish characterization of the differential amplifiers.

- Complete a 1.3" diameter dual or triple oscillator sensor head for sensors.

- Layout 1.3" daughter card.

- Resubmit application specific integrated circuit (ASIC) for frequency counters.

- Continue chromium electrochemistry evaluation.

- Continue STW sensor evaluation

- Prepare for Tinker AFB demonstration.

\subsection{E-SMART Network Management (GA)}

\section{WBS 100.230 — E-SMART Network Management}


Development of the next version of the E-SMART DMAS software continued. A technical approach was chosen and development has begun. Isco was furnished with a version of the program for node development purposes in November.

\subsection{Field Testing (GA, SECOR)}

\section{WBS 200 - E-SMART Field Testing}

At an E-SMART team meeting in Lincoln, NE on Nov. 18, 1997, a general scenario was developed for field testing the E-SMART sensors at Tinker AFB. It is anticipated that the sensors will be tested in pairs to assess sensor-to-sensor consistency. Two basic tests are contemplated. In one test, a sensor pair will be calibrated, lowered into a sampling well, monitored for several days, raised to the surface, and recalibrated. This first test will determine if absolute sensor measurements are consistent with the known characteristics of the sampling well and whether the sensors are subject to calibration drift. In the other test, a sensor pair will be repeatedly raised and lowered in a sampling well using a tripod/wench assembly. This second test will determine if a vertical BTEX concentration gradient can be detected. Finally, an above-ground demonstration setup will permit controlled exposure of an E-SMART sensor to known variations in BTEX and/or interferant chemical concentrations, with the performance of the E-SMART sensor tracked against IR spectrometer measurements. It was tentatively decided to target the week of Mar. 2, 1998 for field testing. DARPA and Tinker personnel will be invited to witness testing on Friday of that week. 


\subsection{Visualization}

\section{WBS 100.300 - E-SMART Visualization (GA)}

Visualization activities will be subsumed within the development of the DMAS system for the duration of the project. This activity will be reported under E-SMART integration activities.

\subsection{Program Management}

\section{WBS 300.100 —E-SMART Program Management (GA)}

Attended the team meeting at Isco in November. Routine cost accounting and progress reporting were performed.

\section{WBS 300.100 — PSS/GTRI Program Control and Reporting}

As previously reported, there is inadequate staffing at PSS to support the ongoing characterization and testing efforts, so additional characterization and testing work is been done by GTRI. The PSS second-tier subcontract with GTRI was increased by $\$ 87,485$ to cover this additional work. There is no change in the overall PSS/GTRI scope of work or funding. Routine cost accounting and progress reporting were performed.

\subsection{Dual Use and Commercialization (GA, Air Force Research Lab)}

\section{WBS 300.200 - Dual Use and Commercialization}

Draft bylaws were developed for the E-SMARTTM Standards Organization (See Appendix A). This organization is intended to promote the use of E-SMART sensors and other E-SMART products. This organization will continue the development of the ESMART standard to ensure interoperability between E-SMART sensors. It will also encourage diverse vendors to work together in promoting E-SMART products.

The Air Force Research Laboratory (includes the former Armstrong Laboratory) has an SBIR Phase I solicitation (AF98-027) for "Development and Integration of MEMS Based Sensor Technologies with E-SMART." The objective is to provide a suite of 
GA-C22131

E-SMART TRP

Q4 CY97

sensor technologies that can be implemented with E-SMART for addressing

Environmental, Safety, and Occupational Health (ESOH) sensing and monitoring needs.

Armstrong Laboratory, Tinker AFB, and General Atomics presented a poster presentation on E-SMART at the $3^{\text {rd }}$ Annual SERDP Symposium in December 1997. 


\section{Problems}

Problems with the BTEX sensor polymers were identified in December 1997. Investigation of this will be described in next quarters' report.

\section{Plans for the Next Quarter}

- Planning for the field demonstration in 1998.

- Sensor integration and development.

- Investigate BTEX sensor problems

- Further development of mercury sensor

- Software development.

- Prototype sensor testing.

\section{Milestones and Deliverables}

E-SMART System for In-situ Detection of Environmental Contaminants Quarterly Technical Progress Report, Quarter 2, Calendar Year 1997 - completed and delivered per contract requirements.

Financial Status Report-Standard Form 269A, Reporting Period 7/1/97-9/30/97 completed and delivered per contract requirements.

\section{Papers and Conferences}

- General Atomics, the Air Force Research Laboratory Environmental Technology Division (formerly Armstrong Laboratory Environics Directorate) and Tinker AFB had a conference poster accepted for the $3^{\text {rd }}$ Annual Strategic Environmental Research and Development Project (SERDP) Symposium to be held December 3-5, 1997 in Washington D.C. The poster was entitled, The E-SMART Technology Reinvestment Project and Beyond.

\section{Financial Status Report}

Per contractual direction, DOE form SF-269A, "Financial Status Report", has been completed by GA for this quarter and has been distributed to the following individuals at DOE-Idaho:

- Patrick Trudel, Program Manager

- Chief Financial Officer, Financial Management Division

- Rebecca Rich, Accounting, Financial Management Division

- Wade Hillebrant, Contract Specialist 


\section{Distribution List}

Rebecca Rich

Chief Financial Officer, Financial Mgmt. Div.

U.S. Dept. of Energy, 850 Energy Dr., M/S 1221

Idaho Falls, ID 83401-1563

Dr. Caroline Purdy

Program Manager

U.S. Dept. of Energy

EM-53, Cloverleaf Bldg.

19901 Germantown Rd.

Germantown, MD 20874

Dr. Ira Skurnick - (DARPA TRP)

Program Manager

Defense Advanced Research Project Agency

3701 North Fairfax Drive

Arlington, VA 22203-1714

Patrick Trudel

Program Manager

U.S. DOE, Idaho Field Office

850 Energy Drive, M/S 1219

Idaho Falls, ID 83401-1563

Wade Hillebrant

Contract Specialist, Procurement Services Div.

U.S. DOE, Idaho Operations Office

850 Energy Drive, M/S 1221

Idaho Falls, ID 83401-1563

Bruce Nielsen

Air Force Research Laboratory

Environmental Technology Division

139 Barnes Drive

Tyndall AFB, FL 32403-5323 


\section{Distribution (continued)}

Dr. Glenn Bastiaans

Ames Laboratory

Iowa State University

125 Spedding Hall

Ames, IA 50011

Kathy Waldrof

Information Control \& Accountability Branch

Office of Scientific and Technical Information (OSTI)

U.S. Department of Energy

P.O. Box 62

Oak Ridge, TN 37831

Michael Long

DARPA

DP-15/GTN

1000 Independence Avenue

Office of Defense Programs

Washington, DC 20585

fax: (301) 903-2903

(gets fax of cover page of report only)

John Edwards

President

Photonic Sensor Systems, Inc.

Suite N-103

430 Tenth Street, NW

Atlanta, GA 30318

Ralph Setter

Isco Inc.

7108 Spoon Terrace

Edmond, OK 73003

Bill Foster

Director of Engineering

Isco, Inc.

531 Westgate Boulevard

Lincoln, NE 68528-1586 


\section{Distribution (continued)}

Craig Smith

SECOR International, Inc.

Suite 302

2655 Camino Del Rio North

San Diego, CA 92108

Nile F. Hartman

Division Chief

Opto-Electronics and Chemical Sciences Division

Georgia Tech Research Institute

925 Dalney Street, Room 223

Atlanta, Georgia 30236

Dr. Jeffrey Andle

BIODE, Inc.

20 Freedom Parkway

Bangor, ME 04401

James D. Shinn

Vice President and Division Manager

Applied Research Associates, Inc. (ARA)

New England Division

RR \#1, Box 120-A

Waterman Road

South Royalton, Vermont 05068

John Bosma

Potomac Institute

1600 Wilson Blyd

Arlington, VA 22209 
GA-C22131

E-SMART TRP

Q4 CY97

APPENDIX A

\section{DRAFT}

E-SMART ${ }^{\mathrm{TM}}$ Standards Organization

Bylaws

Page 17 


\section{BYLAWS \\ OF THE \\ E-SMART® STANDARDS ORGANIZATION}

\section{PURPOSE}

The purpose of the organization is (1) to maintain and develop the Environmental Systems Analysis, and Reporting neTwork (E-SMART®) standards for interoperable sensing and control applications, and (2) promote the development, distribution, marketing and use of E-SMART® technology-based products or services. The organization is intended to provide a forum where environmental equipment developers, manufacturers, systems integrators, equipment specifiers, end users and interested individuals can work together to achieve this purpose.

\section{NAME AND OFFICE}

The name of the organization is The E-SMART® Standards Organization. The location of the principal executive office of the Organization is 3550 General Atomics Court, San Diego, California 92121. The mailing address is POB 85608, San Diego, CA 92186. The Organization may have such other offices or mail addresses as it may designate from time to time.

\section{MEMBERS}

\subsection{Membership Statement: Any person, firm or corporation engaged in the} development, distribution, marketing or use of E-SMART® technology-based products or services is eligible to become a Member, provided, however, that all Members shall (a) be knowledgeable about environmental sensing or control applications, including but not limited to environmental equipment developers, manufacturers, systems integrators, equipment specifiers, end users and interested individuals, (b) support E-SMART® technology as a preferred 
technology for environmental sensing and control applications, and (c) agree to follow the rules of the Organization and promptly pay dues as set forth in Section 4. The purpose of the Organization is to facilitate the development and implementation of open, interoperable E-SMART ${ }^{\circledR}$ technology-based environmental sensing and control products and systems. The Organization provides an open forum for Members to work together on technical and marketing programs to advance the E-SMART ${ }^{\circledR}$ standard for interoperability.

\subsection{Membership Tiers: There shall be four tiers of membership in the Organization:} Sponsors, Founders, Partners, and Affiliates. One membership in the Founders tier is available to each of the participating organizations in the E-SMART Technology Reinvestment Project led by General Atomics. The Founders tier membership must be continuously maintained in good standing to remain available in permanence. The Founder Membership may be transferred from a Founder to a related business entity actively engaged in the development, use or manufacture of E-SMART $®$ technology. Membership in the Sponsors, Partners, and Affiliates tiers is available to any individual or organization meeting the membership criteria of the organization and paying the appropriate level of annual dues.

3.3 Voting Rights: Sponsors, Founders, and Partners ("Voting Members") shall have one vote each on matters on which the entire Organization is entitled to vote and the Members of each of the Sponsor, Founder, and Partner tiers shall have one vote each on matters on which such tier is entitled to vote. Every Voting Member shall have the right to do so either in person or by an agent authorized by a written proxy signed by the Member and filed with the Secretary/Treasurer of the Organization. Members of the Organization will have the opportunity to participate in technical and marketing working groups established by the Executive Council.

\subsection{Executive Council: The Executive Council will consist of the Sponsors,} Founders, and delegates elected from the Partners tier. Delegates from the Partners tier will serve 
on the executive council until the next regularly scheduled election for such delegates. This election will normally be held once a year. The Executive Council may elect a Partner to fill a vacant Partner Delegate position on an interim basis until the next regularly scheduled election. The Partners are entitled to elect a number of delegates based on the number of Partners in the Organization, according to the following table:

$\begin{array}{cc}\begin{array}{cc}\text { Number of Partners } \\ 1-4\end{array} & 1 \\ 5-14 & 2 \\ 15-24 & 3 \\ >24 & 4\end{array}$

All Members on the Executive Council shall have one vote each on matters on which Executive Council is entitled to vote. The Executive Council will establish working groups to develop recommendations on specific technical and marketing issues and will provide direction to the Secretary/Treasurer with respect to marketing or other programs that are to be funded by the Organization. The Executive Council, by majority vote of the Members, shall (i) approve the budget of the Organization, (ii) approve the marketing activities to be conducted by the Organization and (iii) approve the technical requirements to obtain E-SMART® certification as offered by the organization.

3.5 New Members: New Members may join by application to the Secretary/Treasurer. New Members will be accepted provided they are committed to the goals of the Organization and the membership statement set forth in Section 3.1 and pay the appropriate fees. 
3.6 Representatives: Each Member shall designate one person and one alternate to be its representative in the Organization and who shall represent, vote and act for the Member in all affairs of the Organization. Members shall advise the Secretary/Treasurer of their designation.

3.7 Resignation and Removal: Any Member may resign effective upon giving written notice to the Chairman and Secretary/Treasurer of the Organization. The Executive Council, upon the vote of two-thirds (2/3) of the Members, may remove a Member for cause (a) if the Member ceases to become engaged in the development, distribution, marketing or use of E-SMART@ technology based products or services, (b) for failure to comply with Organization rules, or (c) for any other conduct prejudicial to the interests of the Organization. Prior to a vote to remove a Member, such Member shall have the opportunity to appear in person before the Executive Council.

\section{DUES AND FEES}

The annual dues for membership in the Organization shall be as set forth in the attached Dues Schedule. Each Member shall bear its own expenses for attending meetings of the Organization,

Dues shall be payable annually on or before September 30 or March 31 , as shall be determined by the Secretary/Treasurer based on the date the Member joined the Organization. Members who fail to pay their dues within thirty (30) days from the time they become due shall be notified by the Secretary/Treasurer, and, if payment is not made within the next succeeding thirty (30) days shall, without further notice, be dropped from the rolls and thereupon forfeit all rights and privileges of membership; provided however that the Chairman may extend the time for payment of dues and continue membership privileges upon request of a Member and for good cause shown. Dues may be revised upon a vote of two-thirds (2/3) of the Executive Council.

\section{MEETINGS}


Meetings of the Organization shall be held semi-annually. Meetings of the Executive Council shall be held with such frequency as the Members of the Executive Council shall determine from time to time. All meetings shall be held at the principal executive office of the Organization unless another place is stated in the notice of the meeting. Notice of the meeting shall be sent to Members at least fifteen (15) days prior to the meeting time. Members of the Organization and Members of the Executive Council may participate in a meeting through use of a conference telephone, so long as all Members participating in such a meeting can hear one another and so long as such telephone participation does not disrupt the smooth functioning of the meeting. A majority of Voting Members present at any meeting of the Organization constitutes a quorum for the transaction of business, and a majority of Executive Council Members present at any meeting of the Executive Council constitutes quorum for the transaction of Executive Council business. Every act or decision done or made by a majority of the Voting Members (or, if required by these Bylaws, two-thirds (2/3) of the Voting Members) at an Organization Executive Council meeting duly held at which a quorum is present is the act of the Organization or Executive Council, as applicable.

\section{OFFICERS}

The elective officers of the Organization shall be the Chairman and the Secretary/ Treasurer. The Secretary/Treasurer shall be elected annually by a majority vote of the Voting Members of the Organization at a regular meeting of the Organization. The Secretary/Treasurer shall take office upon election and shall serve for a term of one (1) year and until his/her successor is duly elected and qualified. The Chairman shall be elected annually by a majority vote of the Executive Council. The Chairman shall take office upon election and shall serve for a term of twelve (12) months and until his/her successor is duly elected and qualified. 
The Chairman or his or her designate shall preside at meetings of the Organization and at meetings of the Executive Council. The Secretary/Treasurer shall handle the scheduling of Organization and Executive Council meetings (including reserving meeting rooms, sending meeting notices and confirming attendance); prepare and distribute the agenda prior to Organization and Executive Council meetings; distribute working group recommendations to all new Members; record all Organization and Executive Council meeting proceedings; prepare and distribute Organization and Executive Council meeting minutes; handle all membership dues and renewals; maintain the books and records of account for all Organization funds; and provide an annual financial statement. 


\section{RECORDS AND REPORTS}

The Organization and Executive Council shall each keep a minute book with a record of all of its meetings and publish minutes of meetings within ten (10) working days.

\section{RESTRICTIONS}

The Organization will at all times conduct its affairs so as to comply with federal, state and local law. The Organization shall adopt no rules and take no action restricting or limiting, or which might have he effect of restricting or limiting, (a) exhibitions by individual Organization Members at trade shows; (b) the pricing of products or services sold by Organization Members (c) marketing, advertising, or promotion programs of Organization Members; (d) product distribution decisions by Organization Members; (e) technical standards established or adopted by individual Organization Members, or ( $f$ ) independent licensing policies of Organization Members.

\section{CONFIDENTIALITY}

Each Member shall be responsible for preserving the confidentiality of its own proprietary information and shall, to the extent reasonable possible, refrain from exchanging confidential information and trade secrets while participating in Organization meetings and activities.

10. TRADEMARKS

E-SMART $\otimes$ is a registered trademark of General Atomics. Use of the E-SMART ${ }^{\circledR}$ trademark by the Organization is with the permission of General Atomics. All use of the E-SMART $@$ trademark shall inure to the benefit of General Atomics. Members of the 
Organization may use the E-SMART® trademark pursuant to an agreement between the Organization and General Atomics.

\section{USE OF FUNDS}

The Organization shall use its funds only to accomplish the objectives and purposes specified in these Bylaws and no part of aid funds shall inure, or be distributed, to the Members of the Organization, except pursuant to Section 12 below.

\section{DISSOLUTION}

The Organization may be dissolved upon a vote of two-thirds (2/3) of the Voting Members of the Organization. Any Organization funds that remain after the dissolution has been carried out shall be divided among the Members pro-rata based on the Member's dues paid during the one-year period prior to the dissolution.

\section{AMENDMENT}

New Bylaws may be adopted or these Bylaws may be repealed by vote of two-thirds $(2 / 3)$

of the Voting Members of the Organization and two-thirds (2/3) of the Members of the Executive Council. 


\section{Certificate by Secretary/Treasurer of Adoption}

The undersigned hereby certifies that he/she is the duly elected, qualified, and acting Secretary/Treasurer of the E-SMART ${ }^{\circledR}$ Standards Organization, and that the foregoing Bylaws were adopted as he Bylaws of the Organization on 199

IN THE WITNESS WHEREOF, the undersigned has hereunto set his/her hand this day of 199 
E-SMART® STANDARDS ORGANIZATION

DUES SCHEDULE

\begin{tabular}{|l|c|}
\hline $\begin{array}{c}\text { Membership } \\
\text { Tier }\end{array}$ & $\begin{array}{c}\text { Annual Dues } \\
\text { (US \$) }\end{array}$ \\
\hline Sponsor & $\$ 5,000$ \\
\hline Founder & $\$ 2,000$ \\
\hline Partner & $\$ 1,000$ \\
\hline Affiliate & $\$ 100$ \\
\hline
\end{tabular}

